\title{
Preferential segregation of metacentric chromosomes in simple Robertsonian heterozygotes of Sorex araneus
}

\author{
S Fedyk and W Chętnicki \\ Department of Genetics and Evolution, Institute of Biology, Biatystok University, Świerkowa, Biatystok, Poland
}

One of the hypotheses explaining preferential transmission of metacentrics among simple Robertsonian (Rb) heterozygotes of the common shrew (Sorex araneus L.) invokes the existence of meiotic drive. Thus far, evidence that metacentrics are favoured at meiosis has been obtained indirectly, on the basis of crosses made under controlled conditions. The aim of the present work was to test the hypothesis in a direct study. We analysed products of chromosome segregation among 12 simple heterozygote male subjects from a wild population, with regard to $j l, i o, n r$ and $m n \mathrm{Rb}$ fusions. We were able to demonstrate significant segregation distortion in favour of all four metacentrics. The level of preferential segregation was independent either of the composition of chromosome arms or the dimensions of metacentrics. We also found that $X$ chromosomes were favoured over Y1Y2 chromosomes during segregation. We discuss the role of meiotic drive in the evolutionary success of metacentric chromosomes in S. araneus, as well as in the emergence of post-hybridization modifications in the zones of contact between races.

Heredity (2007) 99, 545-552; doi:10.1038/sj.hdy.6801036; published online 15 August 2007

Keywords: common shrew; Sorex araneus; simple Rb heterozygotes; meiotic drive; chromosome segregation

\section{Introduction}

There is a widely accepted view that the ancestral karyotype of the common shrew (Sorex araneus) was entirely composed of acrocentric chromosomes, being similar to that found in the Iberian species Sorex granarius (Searle, 1993). Moreover, most cytogeneticists agree that metacentrics of contemporary chromosomal races of $S$. araneus, characterized by different combinations of chromosomal arms, emerged by centric fusions or whole arm reciprocal translocations (see Searle, 1993 for the schemes of these structural mutations). On first consideration, the evolutionary success of metacentric chromosomes seems paradoxical, since their rise would lead to a gradual increase in chromosomal heterozygosity, and thus a reduction in fertility (cf. King, 1993). One of the theoretical models attempting to resolve the paradox is based on the assumption that, at the population level, standard karyotypes can be eliminated by meiotic drive among heterozygotes. On this basis, it has been suggested that a distortion of segregation could account for the increased frequencies, and consequently the spread of new chromosomal mutations (Bengtsson, 1980).

These theoretical considerations have received empirical support from studies of the karyotypes of foetuses or newborns and their mothers. Searle (1986a) reported

Correspondence: Professor S Fedyk, Department of Genetics and Evolution, Institute of Biology, Biatystok University, Swierkowa 20 B, 15-950 Biatystok, Poland.

E-mail: fedyk@uwb.edu.pl

Received 24 May 2007; accepted 19 June 2007; published online 15 August 2007 preferential transmission of metacentrics between parents and offspring. While the reports of multiple paternity in S. araneus (Tegelström et al., 1991) cast doubt on the reliability of the data presented by Searle (1986a), mating of heterozygotes with homozygotes under laboratory controlled conditions (Wyttenbach and Hausser, 1996; Wyttenbach et al., 1998) provided results strongly supporting preferential transmission of metacentrics on both the maternal and (to even a greater extent) paternal sides. Wyttenbach and Hausser (1996) advanced speculative hypotheses to explain the unequal transmission, suggesting that either (1) oocytes may preferentially accept sperms with metacentric chromosomes, or (2) the excess of transmitted metacentrics arises through the distortion of meiotic segregation. In relation to the second hypothesis, Wyttenbach et al. (1998) assumed that nonhomologous acrocentrics of the trivalent could form a 'side-arm configuration' in pachytene of prophase I, which facilitates recombination within the pericentric area of the acrocentrics. Such a trivalent could form a ring configuration during diakinesis, and consequently could produce a half of unbalanced gametes. To date, these alternative hypotheses have not been verified in direct studies on the meiotic segregation of chromosomes.

Studies of meiosis in S. araneus have so far focused on the conjugation or the lack of pairing and non-disjunction of chromosomes in the context of impairment of fertility in heterozygotes (see Searle, 1986b; Banaszek et al., 2002). Wyttenbach et al. (1998) considered the mechanisms of unequal transmission of metacentrics and concluded that any verification of their hypotheses would require a detailed analysis of the products of meiosis in heterozygotes. To date, however, only segre- 
gation of the sex chromosomes in $S$. araneus has been studied in detail, initially on very limited material (Fedyk, 1980; Searle, 1986b), and more recently (following modification of the meiotic preparation technique) on large numbers of metaphase II (MII) cells (Fedyk et al., 2005). In the present paper, we report the results of analysis of products of chromosome segregation at meiosis among simple Robertsonian $(\mathrm{Rb})$ heterozygous male subjects. We then use these results to test the hypotheses put forward by Wyttenbach et al. (1998).

\section{Materials and methods}

\section{Handling of animals}

We analysed the products of chromosome segregation in 12 sexually mature male subjects of the common shrew. Ten individuals were captured at seven different locations in eastern Poland (Table 1). One individual from Wiartel was trapped in May 2004, and the shrews from the Rokitnia I, Plebanka VI and Zgniłocha were caught in May and June 2005. These were sexually mature male subjects, and their meioses were studied immediately after capture. In contrast, the shrews from Barczewko, Łyna and Klonowo were captured in September 2003 as sexually immature male subjects born in the same year. In order for them to reach sexual maturity, they were maintained for the following 4 months in the laboratory under conditions of $16 \mathrm{~h}$ light: $8 \mathrm{~h}$ dark photoperiod, imitating long days. The remaining two male subjects (nos. 8 and 9; Table 1) were born in the laboratory in February 2004. For the two first months of life, they were maintained under short days ( $8 \mathrm{~h}$ light:16 h dark) and then, for the next 2 months exposed to long daylengths (16 h of light), to accelerate their physical and sexual maturity (Mercer and Searle, 1994).

\section{Karyotypes}

Chromosomal preparations were obtained from the spleen using the in vivo method of Fedyk (1980). Race identification-according to commonly accepted nomenclature (Searle et al., 1991) — was carried out on the basis of G-banding after Seabright (1971). The shrews represented three chromosomal races (Table 1). Three individuals from Barczewko belonged to the Łegucki Młyn
( $\mathrm{Eg}$ ) race, two of them having 24 chromosomes and being $\mathrm{Rb}$ heterozygotes for the io chromosomes. The third had 26 chromosomes. It was a heterozygote for the $j l$ arm combination and had $i$ and $o$ in an acrocentric state. The shrew captured in the Zgniłocha population was the Łegucki Młyn/Drnholec (Dn) inter-racial recombinant carrying the $k h$ and io metacentrics specific to the $\mathrm{g}$ race, as well as the $g m$ and $n r$ chromosomes characteristic for the Dn race. It had 24 chromosomes and was a heterozygote for the io combination. The above four shrews form a sub-class with meiotic trivalents of medium-sized autosomes. The remaining eight male subjects are $\mathrm{Rb}$ heterozygotes for small metacentrics: seven male subjects of the Dn race had $2 N=24$ and were $n r$ heterozygotes. One individual of the Popielno race had 26 chromosomes and was an $m n$ heterozygote (Table 1). We deliberately selected individuals heterozygous for arm combinations differing in size, because we wanted to test whether meiotic segregation favours metacentrics of larger sizes over smaller ones, as hypothesized by Wyttenbach et al. (1998). Four male subjects (no. 4, 10, 11 and 12) came from the hybrid populations; the remainder was caught outside hybrid zones.

\section{Preparation of meiotic chromosomes}

The right testes of all the male subjects were fixed in Bouin solution and preserved for histological study of spermatogenesis. The left testes were placed in an isotonic solution of sodium citrate. The seminiferous tubules released into the isotonic fluid were divided into two parts, one being used in the preparation of surface spreads for the study of synaptonemal complexes under an electron microscope, the other for the analysis of MII cells. Meiotic chromosomes were prepared using the method of Evans et al. (1964), as modified by Searle (1986b). Each male subject yielded 15-20 conventionally Giemsa-stained preparations, giving a large number ( $>100)$ of MII cells suitable for analysis. To generate the large number of MII cells, in vivo exposure to colchicine was prolonged to 4 , or even $6 \mathrm{~h}$ (Fedyk et al., 2005).

\section{Analysis of the segregation of chromosomes}

The analysed shrews had 24 chromosomes with two pairs of acrocentrics ( $p$ and $q$ ), or 26 chromosomes with

Table 1 Details of individual shrews used in the study

\begin{tabular}{|c|c|c|c|c|c|c|}
\hline $\begin{array}{l}\text { Size of heterozygous } \\
\text { chromosomes }\end{array}$ & $\begin{array}{l}\text { No. of } \\
\text { shrew }\end{array}$ & $2 \mathrm{~N}$ & Variable part of karyotype & Race & Population & $\begin{array}{l}\text { Geographic } \\
\text { coordinates }\end{array}$ \\
\hline \multirow[t]{4}{*}{ Medium } & 1 & 24 & $j l, h k, i / i o / o, g r, m n, p, q$ & Łg & Barczewko & \multirow[t]{4}{*}{$20^{\circ} 45^{\prime} \mathrm{E} ; 53^{\circ} 51^{\prime} \mathrm{N}$} \\
\hline & 2 & 24 & $j l, h k, i / i o / o, g r, m n, p, q$ & Łg & Barczewko & \\
\hline & 3 & 26 & $j / j l / l, h k, g r, m n, i, o, p, q$ & $\mathrm{Eg}$ & Barczewko & \\
\hline & 4 & 24 & $j l, h k, i / i o / o, g m, n r, p, q$ & Łg/Dn recombinant & Zgniłocha & \\
\hline \multirow[t]{8}{*}{ Small } & 5 & 24 & $j l, h i, k o, g m, n / n r / r, p, q$ & Dn & Łyna & $20^{\circ} 27^{\prime} \mathrm{E} ; 53^{\circ} 27^{\prime} \mathrm{N}$ \\
\hline & 6 & 24 & $j l, h i, k o, g m, n / n r / r, p, q$ & Dn & Klonowo & \multirow[t]{4}{*}{$19^{\circ} 47^{\prime} \mathrm{E} ; 53^{\circ} 15^{\prime} \mathrm{N}$} \\
\hline & 7 & 24 & $j l, h i, k o, g m, n / n r / r, p, q$ & Dn & Klonowo & \\
\hline & 8 & 24 & $j l, h i, k o, g m, n / n r / r, p, q$ & Dn & Laboratory reared & \\
\hline & 9 & 24 & $j l, h i, k o, g m, n / n r / r, p, q$ & Dn & Laboratory reared & \\
\hline & 10 & 24 & $j l, h i, k o, g m, n / n r / r, p, q$ & Dn & Rokitnia I & $21^{\circ} 48^{\prime} \mathrm{E} ; 51^{\circ} 36^{\prime} \mathrm{N}$ \\
\hline & 11 & 24 & $j l, h i, k o, g m, n / n r / r, p, q$ & Dn & Plebanka VI & $21^{\circ} 49^{\prime} \mathrm{E} ; 51^{\circ} 36^{\prime} \mathrm{N}$ \\
\hline & 12 & 26 & $j l, i k, g r, m / m n / n, h, o, p, q$ & Po & Wiartel & $21^{\circ} 40^{\prime} \mathrm{E} ; 53^{\circ} 36^{\prime} \mathrm{N}$ \\
\hline
\end{tabular}

Abbreviations: Dn, Drnholec; Łg, Łegucki Młyn; Po, Popielno.

${ }^{a}$ Chromosome arms labelled with small letters according to standard nomenclature (Searle et al., 1991); combination ab-a homozygous pair of metacentrics; combination $a / a b / b$-a heterozygous pair; $a, b$-two homozygous pairs of acrocentric chromosomes. 
two additional pairs of acrocentrics ( $i$ and $o$ or $h$ and $o$ ). In addition, twin acrocentrics were present in polymorphic pairs of autosomes (Table 1). Irrespective of the proportion of metacentric to acrocentric autosomes, somatic cells of common shrews contain a constant number of chromosome arms $(\mathrm{NF}=40)$, whereas normal MII cells should have NF reduced to 20. Accordingly, independent segregation of the sex chromosome trivalent and the autosomal trivalent should result in four types of MII cells with the same frequency $(0.25: 0.25: 0.25: 0.25)$ but differing in their numbers of chromosomes. For example, shrew no. 1 with 24 chromosomes and the full karyotype $\mathrm{X} / \mathrm{Y} 1 / \mathrm{Y} 2, b c, a f, j l, h k, i / i o / o, g r, m n, p, q$ and $t u$ should produce four types of MII cells, with chromosome numbers 11,12 or 13 , that is:

Type A: X, bc, af, jl, hk, io, gr, mn, $p, q, t u(N=11)$

Type B: Y1, Y2, bc, af, $j l, h k, i o, g r, m n, p, q, t u(N=12)$

Type C: $\mathrm{X}, b c, a f, j l, h k, i, o, g r, m n, p, q, t u(N=12)$

Type D: Y1, Y2, bc, af, jl, hk, i, o, gr, mn, p, q, tu $(N=13)$

(Figure 1).

Types $\mathrm{B}$ and $\mathrm{C}$ have 12 chromosomes each, but can be distinguished easily from one another on the basis of the numbers of acrocentric chromosomes: in the type $B$, there are three small acrocentrics ( $p, q$ and Y1) and the subtelocentric $\mathrm{Y} 2$, and in the type $\mathrm{C}$-four acrocentrics $(p, q, i$ and $o$ ), and the metacentric $X$ of large size (comparable with the chromosomes $b c$ and $a f)$. Obviously, male subjects with $2 N=26$ should produce MII cells with 12, 13 or 14 chromosomes (Figure 2).

It needs to be emphasized that, among the four products of segregation from male subject meiosis, there are two pairs of complementary types of MII cells: A+D and $\mathrm{B}+\mathrm{C}$, whose chromosome numbers add up to $2 N=24$ (or 26). In other words, there are two possibilities for the correct segregation of the diploid set of chromosomes (A and D versus $B$ and $C$ ). A and D cells represent the extreme types-with five acrocentrics (type D) or two (type A). In contrast, type B and C cells-as has been mentioned-differ in the presence of one acrocentric. Likewise, in male subjects with $2 N=26$, cells of types A and $\mathrm{D}$ differ in three acrocentrics, those of types $\mathrm{B}$ and $\mathrm{C}$ in one only. The $\chi^{2}$ test was used to assess the deviations from the expected proportions of MII cells.

MII spreads with incorrect numbers of chromosomes $(\mathrm{NF} \neq 20)$ can readily be identified. Such spreads may arise through the action of two factors. In the first place, some part of MII cells recorded with counts of less than 20 chromosome arms arise as a result of cell damages. Artefacts of this kind may at times come to represent a considerable fraction of the material studied. In other instances, they can be attributed to non-disjunction, the effect of which is for half of cells to have NF $<20$, the other half $\mathrm{NF}>20$. As the cases of chromosome deficits arising through non-disjunction cannot be distinguished from artefacts, the estimation of non-disjunction frequency was made using hyperploid MII spreads only, their numbers then being doubled to compensate for the ignored hypoploid spreads.

\section{Results}

\section{The segregation of chromosomes}

The four types of MII cells arise with different frequencies. Metacentric chromosomes are favoured in the segregation of meiotic trivalents, and this is true for both autosomes (frequency of metacentrics $=0.64$ ), and sex chromosomes (frequency of $\mathrm{X}$ chromosomes $=0.61$ ). In each case, there are highly significant deviations from a frequency of 0.5 , although the excess of $X$ chromosomes in four individual male shrews did not achieve statistical significance (Table 3 ). In consequence, all 12 shrews show the frequencies of type A MII cells that far exceed the theoretical value of 0.25 (mean frequency is 0.42 ). The frequencies of cells of types $B$ and $C$ are rather similar and close to the expected values $(0.23$ and 0.20 respectively). Type $\mathrm{D}$ cells were noted most rarely (with the mean frequency of 0.15 ). In only three cases was the frequency of type D cells higher than that of type $C$ (Table 2).

The level of non-disjunction (the vast majority of hyperploid MII spreads had one acrocentric chromosome extra; Figure 3a) is rather higher among the $i / o$ and $j / l$ heterozygotes than among the male subjects heterozygous for small-sized chromosomes ( $n r, m n$ ) (Table 3). However, the size of a metacentric does not influence the degree of segregation distortion. The mean frequencies of the four types of MII cells are homogeneously distributed among medium-sized (io, $j l)$ and small-sized ( $\mathrm{nr}, \mathrm{mn})$ heterozygous autosomes $\left(\chi_{(3)}^{2}=0.60 ; P>0.9\right)$. On the other hand, the segregation distortion in favour of metacentrics is higher (0.68) for the male subjects coming from hybrid
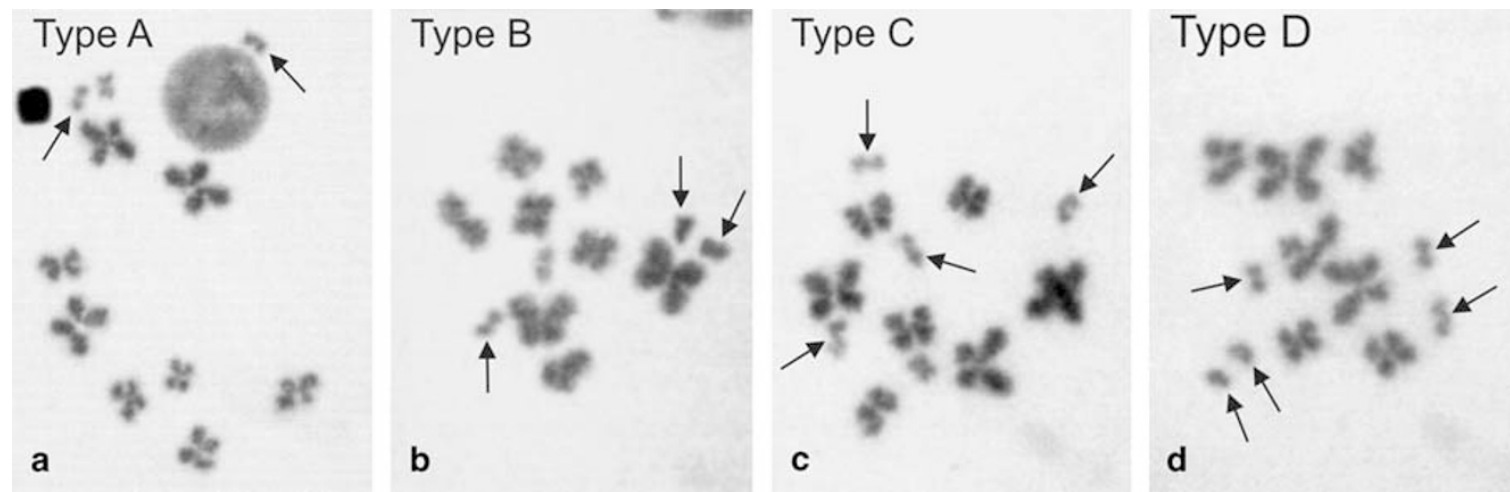

Figure 1 MII spreads of an individual, heterozygous for $n r$ chromosome, with 24 chromosomes in somatic cells. (a) The MII cell with 11 chromosomes, arrows indicate $p$ and $q$ acrocentrics. (b) The MII cell with 12 chromosomes, arrows indicate $p, q$ and $\mathrm{Y}_{1}$ acrocentric chromosomes. (c) The MII cell with 12 chromosomes, arrows indicate four acrocentrics $n, p, q$ and $r$. (d) The MII cell with 13 chromosomes, arrows indicate $n, p, q, r$ and $\mathrm{Y}_{1}$ chromosomes. MII, metaphase II. 


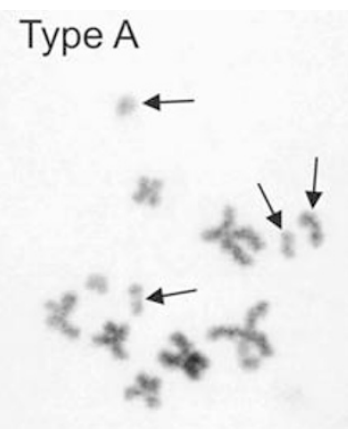

a

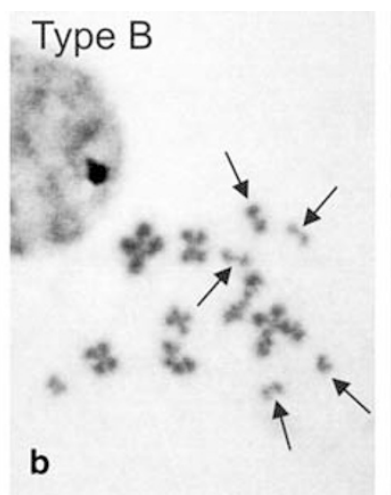

Type C

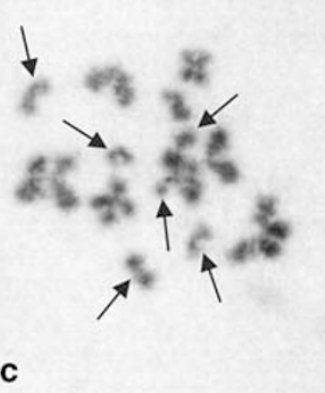

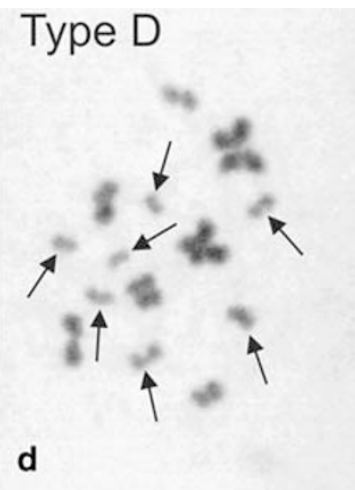

Figure 2 MII spreads of an individual, heterozygous for $j l$ arm combination, with 26 chromosomes in somatic cells. (a) The MII cell with 12 chromosomes, arrows indicate $i, o, p$ and $q$ acrocentrics. (b) The MII cell with 13 chromosomes, arrows indicate $i, o, p, q$ and $\mathrm{Y}_{1}$ chromosomes. (c) The MII cell with 13 chromosomes, arrows indicate six acrocentrics $(j, l, i, o, p$ and $q$ ). (d) The MII cell with 14 chromosomes, arrows indicate seven acrocentric chromosomes $\left(j, l, i, o, p, q\right.$ and $\left.\mathrm{Y}_{1}\right)$. MII, metaphase II.

Table 2 Counts of the four products of segregation (frequencies given in parentheses)

\begin{tabular}{|c|c|c|c|c|c|c|c|}
\hline \multirow[t]{2}{*}{ No. of shrew } & \multirow[t]{2}{*}{$\mathrm{Hpa}$} & \multicolumn{4}{|c|}{ Products of segregation } & \multirow[t]{2}{*}{ Total scored MII cells } & \multirow{2}{*}{$\frac{\text { Departure from 1:1:1:1 proportion }}{\chi_{(3)}^{2}}$} \\
\hline & & $A$ & $B$ & C & $D$ & & \\
\hline 1 & io & $81(0.37)$ & $50(0.23)$ & $44(0.20)$ & $42(0.19)$ & 217 & $18.226 ; P<0.0005$ \\
\hline 2 & io & $70(0.37)$ & $55(0.29)$ & $28(0.15)$ & $38(0.20)$ & 191 & $21.628 ; P<0.0005$ \\
\hline 3 & $j l$ & $87(0.48)$ & $33(0.18)$ & $40(0.22)$ & $22(0.12)$ & 182 & $54.088 ; P<0.0005$ \\
\hline 4 & io & $77(0.50)$ & $33(0.21)$ & $30(0.19)$ & $15(0.10)$ & 155 & $55.142 ; P<0.0005$ \\
\hline Subtotal & & $315(0.42)$ & $171(0.23)$ & $142(0.19)$ & $117(0.16)$ & 745 & $126.511 ; P \ll 0.0005$ \\
\hline 5 & $n r$ & $63(0.39)$ & $35(0.21)$ & $41(0.25)$ & $22(0.14)$ & 161 & $21.832 ; P<0.0005$ \\
\hline 6 & $n r$ & $61(0.40)$ & $36(0.21)$ & $29(0.19)$ & $26(0.17)$ & 152 & $19.947 ; P<0.0005$ \\
\hline 7 & $n r$ & $49(0.39)$ & $35(0.28)$ & $21(0.17)$ & $21(0.17)$ & 126 & $17.111 ; P<0.001$ \\
\hline 8 & $n r$ & $63(0.38)$ & $39(0.24)$ & $34(0.21)$ & $28(0.17)$ & 164 & $17.219 ; P<0.001$ \\
\hline 9 & $n r$ & $51(0.39)$ & $35(0.27)$ & $21(0.16)$ & $22(0.17)$ & 129 & $18.318 ; P<0.0005$ \\
\hline 10 & $n r$ & $81(0.45)$ & $34(0.19)$ & $45(0.25)$ & $21(0.12)$ & 181 & 44.039; $P<0.0005$ \\
\hline 11 & $n r$ & $80(0.43)$ & $36(0.20)$ & $45(0.24)$ & $23(0.13)$ & 184 & $38.826 ; P<0.0005$ \\
\hline 12 & $m n$ & $70(0.43)$ & $39(0.24)$ & $21(0.13)$ & $31(0.19)$ & 161 & $33.360 ; P<0.0005$ \\
\hline Subtotal & & $518(0.41)$ & $289(0.23)$ & $257(0.20)$ & $194(0.15)$ & 1258 & $190.426 ; P \ll 0.0005$ \\
\hline Total & & $833(0.42)$ & $460(0.23)$ & $399(0.20)$ & $311(0.15)$ & 2003 & $316.426 ; P \ll 0.0005$ \\
\hline
\end{tabular}

Abbreviations: Hpa, heterozygous pair of autosomes; MII, metaphase II.
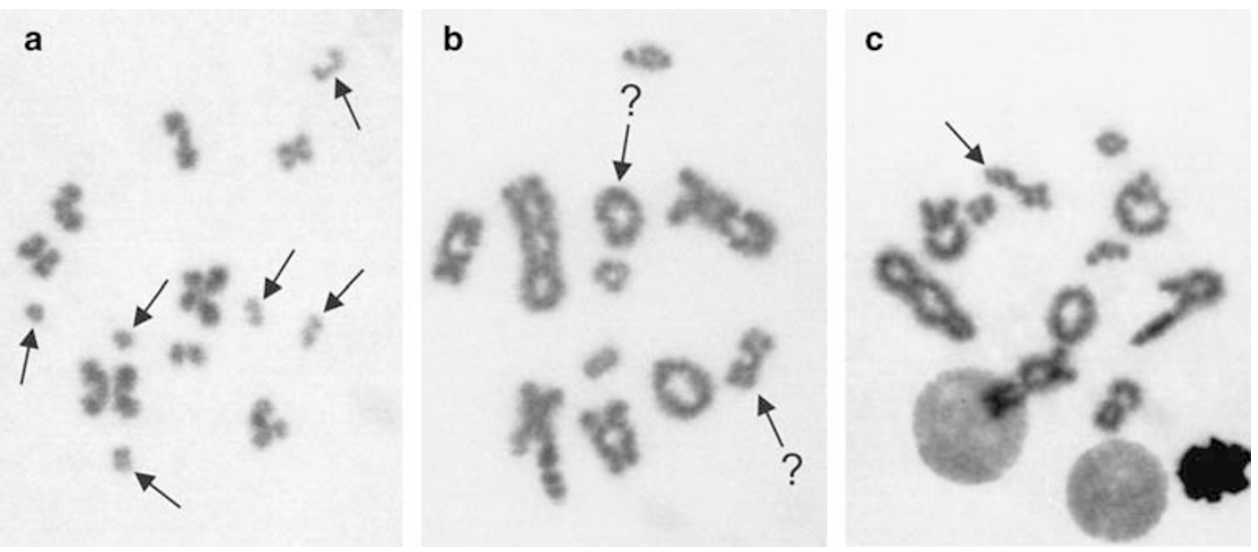

Figure 3 (a) Hyperploid MII spread of the individual heterozygous for $j l$ chromosome arm combination; the type B cell with 14 chromosomes and one acrocentric extra (arrows indicate six acrocentric chromosomes). (b) The only case of diakinesis spread with probable ring configuration of $n r$ trivalent. It is not clear which one, out of the two elements indicated by arrows, really represents $n r$ arm combination. (c) Arrow indicates chain configuration of $n r$ trivalent. MII, metaphase II. 
populations (shrews no. 4, 10, 11 and 12) than for the remaining individuals $(0.62)$; the difference is statistically significant $\left(\chi_{(1)}^{2}=7.81 ; P<0.01\right)$.

The analysis of the complementary pairs of MII cells confirms the segregation distortion in favour of the metacentric chromosomes. The cells of types B and C occur in similar proportions, although when scores from all shrews are totalled, $\mathrm{B}$ is slightly but significantly higher than $C(P<0.05$; mean $\mathrm{B}: \mathrm{C}=1.1: 1$, Table 4$)$. In contrast, within the second pair of complementary cells an excess of type A over type $\mathrm{D}$ was found in all 12 male subjects studied (mean $\mathrm{A}: \mathrm{D}=2.7: 1 ; \quad P<0.005-0.001$, Table 4).

These results might implicate preferential loss of acrocentric chromosomes during preparation as the main reason for the deficit of type D euploid spreads, as compared with type A. This is not the case. Spreads with losses of single acrocentric chromosomes $(\mathrm{NF}=19)$ are homogeneously distributed among the four types of segregation products (type $\mathrm{A}-27.4 \%$ of spreads, type B- $26.3 \%$ of spreads, type $C-19.8 \%$ and type $D-26.5 \%$ of spreads; $P>0.5$ ). Thus, even a considerable number of chromosome losses, arising during preparation, did not affect the proportion of scored euploid products of segregation.

\section{Configurations of trivalents in diakinesis}

According to the model accounting for the unequal transmission of meta- and acrocentric chromosomes through recombination in the pericentric area of twin acrocentrics forming a trivalent, at the diakinesis stage of simple $\mathrm{Rb}$ heterozygotes, a ring configuration of trivalents ought to be observed. To check for this, 187 diakinesis spreads coming from four heterozygous male subjects were analysed. However, in this material, it was

Table 3 The meiotic segregation of chromosomes (frequencies given in parentheses)

\begin{tabular}{|c|c|c|c|c|c|c|c|c|c|}
\hline \multirow[t]{2}{*}{ No. of shrew } & \multirow[t]{2}{*}{$H p a$} & \multirow{2}{*}{$\begin{array}{l}\text { Total scored } \\
\text { MII cells }\end{array}$} & \multicolumn{3}{|c|}{ Segregation of autosomes } & \multicolumn{3}{|c|}{ Segregation of sex chromosomes } & \multirow[t]{2}{*}{ Non-disjunction (\%) } \\
\hline & & & Meta & Acro & $\chi_{(1)}^{2}$ & $X$ & $Y_{1} Y_{2}$ & $\chi_{(1)}^{2}$ & \\
\hline 1 & io & 217 & $131(0.60)$ & $86(0.40)$ & 9.33; $P<0.005$ & $125(0.58)$ & $92(0.42)$ & $5.02 ; P<0.05$ & 7.0 \\
\hline 2 & io & 191 & $125(0.65)$ & $66(0.35)$ & $18.22 ; P \ll 0.001$ & $98(0.51)$ & $93(0.49)$ & $0.13 ; P>0.7$ & 5.9 \\
\hline 3 & $j l$ & 182 & $120(0.66)$ & $62(0.34)$ & $18.48 ; P \ll 0.001$ & $127(0.70)$ & $55(0.30)$ & $28.48 ; P \ll 0.001$ & 6.4 \\
\hline 4 & io & 155 & $110(0.71)$ & $45(0.29)$ & $27.26 ; P \ll 0.001$ & $107(0.69)$ & $48(0.31)$ & $22.45 ; P \ll 0.001$ & 3.8 \\
\hline Subtotal & & 745 & $486(0.65)$ & $259(0.35)$ & $69.17 ; P \ll 0.001$ & $457(0.61)$ & $288(0.39)$ & $38.34 ; P \ll 0.001$ & 5.9 \\
\hline 5 & $n r$ & 161 & $98(0.61)$ & $63(0.39)$ & $7.61 ; P<0.01$ & $104(0.65)$ & $57(0.35)$ & $13.72 ; P \ll 0.001$ & 3.3 \\
\hline 6 & $n r$ & 152 & $97(0.64)$ & $55(0.36)$ & $11.60 ; P<0.001$ & $90(0.59)$ & $62(0.41)$ & $5.16 ; P<0.025$ & 1.2 \\
\hline 7 & $n r$ & 126 & $84(0.67)$ & $42(0.33)$ & $14.00 ; P \ll 0.001$ & $70(0.56)$ & $56(0.44)$ & $1.55 ; P>0.2$ & 1.6 \\
\hline 8 & $n r$ & 164 & $102(0.62)$ & $62(0.38)$ & $7.90 ; P<0.005$ & $97(0.59)$ & $67(0.41)$ & $5.49 ; P<0.025$ & 4.8 \\
\hline 9 & $n r$ & 129 & $86(0.67)$ & $43(0.33)$ & $14.33 ; P \ll 0.001$ & $72(0.56)$ & $57(0.44)$ & $1.74 ; P>0.2$ & 3.0 \\
\hline 10 & $n r$ & 181 & $115(0.64)$ & $66(0.36)$ & $13.26 ; P \ll 0.001$ & $126(0.70)$ & $55(0.30)$ & $27.85 ; P \ll 0.001$ & 7.4 \\
\hline 11 & $n r$ & 184 & $116(0.63)$ & $68(0.37)$ & $12.07 ; P<0.001$ & $125(0.68)$ & $59(0.32)$ & $23.09 ; P \ll 0.001$ & 4.3 \\
\hline 12 & $m n$ & 161 & $109(0.68)$ & $52(0.32)$ & $20.18 ; P \ll 0.001$ & $91(0.56)$ & $70(0.44)$ & $2.74 ; P>0.05$ & 3.5 \\
\hline Subtotal & & 1258 & $807(0.64)$ & $451(0.36)$ & $100.74 ; P \ll 0.001$ & $775(0.62)$ & $483(0.38)$ & $67.78 ; P \ll 0.001$ & 3.1 \\
\hline Total & & 2003 & $1293(0.64)$ & $710(0.36)$ & $169.69 ; P \ll 0.001$ & $1232(0.61)$ & $771(0.39)$ & $106.10 ; P \ll 0.001$ & 4.1 \\
\hline
\end{tabular}

Abbreviation: Hpa, heterozygous pair of autosomes.

Table 4 Segregation of complementary MII cells

\begin{tabular}{|c|c|c|c|c|c|c|c|c|c|}
\hline No. of shrew & Hра & $A, \mathrm{n}(f r)$. & $D, \mathrm{n}(f r)$. & Proportion A:D & $\chi_{(1)}^{2}$ & $B, \mathrm{n}(f r)$. & $C, \mathrm{n}(f r)$. & Proportion B:C & $\chi_{(1)}^{2}$ \\
\hline 1 & io & $81(0.66)$ & $42(0.34)$ & $1.9: 1$ & 12.37; $P<0.001$ & $50(0.53)$ & $44(0.47)$ & $1.1: 1$ & $0.38 ; P>0.5$ \\
\hline 2 & io & $70(0.65)$ & $38(0.35)$ & $1.9: 1$ & $9.48 ; P<0.005$ & $55(0.66)$ & $28(0.34)$ & $2: 1$ & $8.78 ; P<0.005$ \\
\hline 3 & $j l$ & $87(0.80)$ & $22(0.20)$ & 3.9:1 & $38.76 ; P \ll 0.001$ & $33(0.45)$ & $40(0.55)$ & $0.8: 1$ & $0.67 ; P>0.4$ \\
\hline 4 & io & $77(0.84)$ & $15(0.18)$ & $5.1: 1$ & $41.78 ; P \ll 0.001$ & $33(0.52)$ & $30(0.48)$ & $1.1: 1$ & $0.14 ; P>0.7$ \\
\hline$\sum$ & & $315(0.73)$ & $117(0.27)$ & $2.7: 1$ & $90.75 ; P \ll 0.001$ & $171(0.55)$ & $142(0.45)$ & $1.2: 1$ & $2.69 ; P>0.1$ \\
\hline 5 & $n r$ & $63(0.74)$ & $22(0.26)$ & 2.9:1 & $19.78 ; P \ll 0.001$ & $35(0.46)$ & $41(0.54)$ & $0.8: 1$ & $0.47 ; P>0.5$ \\
\hline 6 & $n r$ & $61(0.70)$ & $26(0.30)$ & 2.3:1 & $14.08 ; P \ll 0.001$ & $36(0.55)$ & $29(0.45)$ & $1.2: 1$ & $0.75 ; P>0.3$ \\
\hline 7 & $n r$ & $49(0.63)$ & $21(0.30)$ & 2.3:1 & $11.20 ; P<0.001$ & $35(0.62)$ & $21(0.37)$ & $1.7: 1$ & $3.50 ; P>0.05$ \\
\hline 8 & $n r$ & $63(0.69)$ & $28(0.31)$ & 2.2:1 & $13.46 ; P \ll 0.001$ & $39(0.53)$ & $34(0.47)$ & $1.1: 1$ & $0.34 ; P>0.5$ \\
\hline 9 & $n r$ & $51(0.70)$ & $22(0.30)$ & 2.3:1 & $11.52 ; P<0.001$ & $35(0.62)$ & $21(0.38)$ & $1.7: 1$ & $3.50 ; P>0.05$ \\
\hline 10 & $n r$ & $81(0.79)$ & $21(0.21)$ & 3.9:1 & $35.29 ; P \ll 0.001$ & $34(0.43)$ & $45(0.57)$ & $0.7: 1$ & $1.53 ; P>0.2$ \\
\hline 11 & $n r$ & $80(0.78)$ & $23(0.22)$ & $3.5: 1$ & $31.54 ; P \ll 0.001$ & $36(0.44)$ & $45(0.56)$ & $0.8: 1$ & $1.00 ; P>0.3$ \\
\hline 12 & $m n$ & $70(0.69)$ & $31(0.31)$ & 2.3:1 & $15.06 ; P \ll 0.001$ & $39(0.65)$ & $21(0.35)$ & 1.9:1 & $5.40 ; P<0.025$ \\
\hline$\sum$ & & $518(0.72)$ & $194(0.28)$ & $2.7: 1$ & $147.44 ; P \ll 0.001$ & $289(0.53)$ & $257(0.47)$ & $1.1: 1$ & $1.87 ; P>0.2$ \\
\hline$\sum \sum$ & & $833(0.73)$ & $311(0.27)$ & $2.7: 1$ & $119.09 ; P \ll 0.001$ & $460(0.53)$ & $399(0.47)$ & $1.1: 1$ & $4.33 ; P<0.05$ \\
\hline
\end{tabular}

Abbreviation: Hpa, heterozygous pair of autosomes. 
only possible to note one probable case of a ring (Figure 3b). It was not clear whether the ring configuration in question comprised the $n / n r / r$ trivalent, or one of the small-sized bivalents. In remaining cases, trivalents formed chain configurations (Figure 3c).

\section{Discussion}

The first data on the preferential transmission of metacentrics in the common shrew were obtained in studies of the chromosomes of heterozygous pregnant female subjects from the field and their offspring (Searle, 1986a). However, multiple paternity in common shrews has been demonstrated (Tegelström et al., 1991), which complicates the interpretation of data from natural pregnancies. Crosses of $\mathrm{Rb}$ heterozygotes with homozygotes under controlled laboratory conditions (Wyttenbach and Hausser, 1996; Wyttenbach et al., 1998) have provided definitive proof that transmission of metacentrics-above all those on the paternal side-to offspring is significantly more frequent than of their acrocentric homologues. Concerning the mechanism of preferential transmission, Wyttenbach and Hausser (1996) suggested that either (a) there is a distortion of the segregation in favour of metacentric chromosomes or (b) the oocytes more often accept sperm with metacentrics than with acrocentrics (the 'choice effect' hypothesis).

Our study shows that segregation distortion in simple $\mathrm{Rb}$ heterozygote male subjects does favour metacentric chromosomes at the level of $0.60-0.71$ (Table 3). These data agree with the 0.64-0.65 level of transmission of metacentrics reported by Searle (1986a), and with the level of transmission from the male side (of 0.64-0.68) noted in crosses obtained in controlled conditions (Wyttenbach et al., 1998). Our data thus suggest segregation distortion, rather than 'choice effect', as the cause of excess of metacentric chromosomes in the offspring of $\mathrm{Rb}$ heterozygotes. The higher level of transmission of metacentrics on the male subject as opposed to the female side inclined Wyttenbach and Hausser (1996) to consider possible mechanisms of segregation disturbances involving both sexes. They paid attention to the earlier suggestion by Fedyk (1987), who pointed out the fact that the centromeres of the acrocentrics that form (together with the metacentrics) meiotic complexes are in close proximity to one another during prophase I, could increase the chances of fusions between acrocentrics. Likewise, the model described by Wyttenbach et al. (1998) proposes that metacentrics arise as a result of crossing over between the twin acrocentrics forming a trivalent. The consequence of the crossing over between non-homologous chromatids in a trivalent should be the emergence of ring configurations at the diakinesis. However, such ring configurations were not observed in our study, which corroborates the earlier observations by Searle (1986b). Therefore, the excess of metacentric chromosomes cannot result from recombination among twin acrocentrics. On the other hand, formation of a short non-homologously paired side arm in the centromere region of twin acrocentrics seems to play a significant role. Wallace (2003) demonstrated that in heterozygous mice over $84 \%$ of trivalents have paired side arm, whereas in common shrews only around $28 \%$. Unlike in shrews, preferential segregation in favour of acrocentric chromosomes was observed in mice (Gropp and Winking, 1981). Further detailed analyses of pachytene stage in shrews are therefore needed to elucidate the causality between formation of paired side arm in trivalents and preferential segregation of chromosomes. Another conclusion is that the meiotic drive system in $S$. araneus can be regarded rather as a chromosomal, than a genic drive, since the segregation distortion affects different ( $\mathrm{gm}, \mathrm{hi}, \mathrm{jl}$ ) Rb fusions (Wyttenbach et al., 1998). This conclusion gains further confirmation in our study. We have demonstrated that, not only large metacentrics (jl, io) but also small ones $(n r, m n)$ are favoured significantly during meiosis. The level of meiotic drive does not depend on either the size of metacentrics or the composition of chromosome arms in MII cells, the frequency of $n r$ reached 0.64 , that of io 0.65 , that of $j l$ 0.66 and that of $m n 0.68$, the differences between these figures did not reach statistical significance $\left(\chi^{2}(3)=1.46\right.$; $P>0.7)$.

The consequences of segregation distortion ought to be a steady rise in the frequency of metacentrics, until their fixation. The effects of this were observed in site no. 93 at Białowieża (NE Poland) (Fedyk, 1980). Taking frequencies of metacentrics in the sample from 1968 as a basis for calculation, it was possible to show-for the 80-shrew sample from 1971-a statistically significant deficit of $g / r$ and $j / l$ heterozygotes. In contrast, the deficits observed in 1972 and 1974 were not significant (Table 5), perhaps, as a result of a declining influence of preferential transmission of metacentrics. Maybe, the marked decrease in frequency of acrocentrics in the period 1968-1971 resulted from a rarity of heterozygotes in the population, reducing the effect of segregation distortion on chromosome frequency.

It seems natural to connect the evolutionary success of the $\mathrm{Rb}$ fusion in $\mathrm{S}$. araneus with segregation distortion in favour of metacentrics, as emphasized by Bentgsson (1980) Wyttenbach and Hausser (1996) and Wyttenbach et al. (1998). Mathematical models suggest that even a

Table 5 Deficit of heterozygous shrews in locality no. 93 at the Białowieża Primeval Forest (data compiled from Tables 11 and 12 in the paper by Fedyk, 1980)

\begin{tabular}{|c|c|c|c|c|}
\hline Year & 1968 & 1971 & 1972 & 1974 \\
\hline Sample size & 40 & 80 & 32 & 19 \\
\hline $\begin{array}{l}\text { Fraction of heterozygotes } \\
\text { Heterozygote deficits }^{\text {a }}\end{array}$ & 0.275 & 0.125 & 0.094 & 0.000 \\
\hline$g r$ & - & $7.340(P<0.01)$ & & \\
\hline jl & - & $4.292(P<0.05)$ & & \\
\hline
\end{tabular}

${ }^{\mathrm{a}}$ The $\chi_{(1)}^{2}$ values were calculated in four independent goodness-of-fit tests between the observed and expected numbers of hetero- and homokaryotypes estimated on the basis of frequencies of $g r$ and $j l$ chromosomes in 1968. 
limited level of meiotic drive favouring a new chromosomal variant should act like directional selection, thereby increasing the likelihood of fixation of the mutation (Hedrick, 1981). On this basis, the critical period of the increase in heterozygosity, relating to the lower fitness of heterozygotes (Gropp and Winking, 1981), may be shortened markedly under the pressure of meiotic drive. It can be suggested that selection against $\mathrm{Rb}$ heterozygotes, supported by meiotic drive in favour of metacentric chromosomes, should effectively eliminate heterozygotes and consequently fix metacentrics in population of $S$. araneus. However, throughout the whole range of the species, $\mathrm{Rb}$ polymorphism has been found (Fedyk, 1995), and what is more, the frequencies of polymorphic chromosomes in some populations would seem to be stable (Searle, 1986c). Wyttenbach et al. (1998) explained the presence of balanced polymorphismaccording to their own model-in terms of the possibility of recombination frequencies changing under the pressure of natural selection. The same was also suggested by Felsenstein and Yokoyama (1976) in their model. It is possible, however, that the stabilization of $\mathrm{Rb}$ polymorphism in shrew populations does not result solely from such an intrapopulation mechanism. In most cases, the areas of $\mathrm{Rb}$ polymorphism are located between monomorphic areas with fixed metacentrics and acrocentrics. This point is well illustrated by the zone of hybridization, about $100 \mathrm{~km}$ wide, between the Dn race (hi, $k o, g m, n r)$ and the Ulm race $(h i, g m, k, o, n, r)$. It is obvious that this contact zone must be characterized by regular frequency clines of metacentrics $k o$ and $n r$ (Lukáčova et al., 1994). Migration of individuals between adjacent populations will effectively counteract the reduction of heterozygosity caused by meiotic drive. Such exchanges between populations may, however, be limited at the local level by various environmental barriers (Fedyk et al., 1993; Narain and Fredga, 1996; Szalaj et al., 1996; Moska, 2003).

The present study demonstrates stronger distortion of segregation among the male subjects coming from hybrid zones than those from pure race populations. This is quite surprising, because biased segregation in favour of metacentrics would seem to be inconsistent with the acrocentric peak described by Searle (1986c) in the contact zone between the Oxford and Hermitage races, and also present in several other hybrid zones (Fedyk, 1986; Banaszek, 1994; Szalaj et al., 1996; Fredga and Narain, 2000; Moska, 2003). The presence of acrocentrics in a hybrid zone is 'desirable' because, the higher the frequency of acrocentrics in the contact zone, the rarer the appearance of complex heterozygotes, which are characterized by impaired fertility (Searle, 1993). Simulations show that, if selection against the heterozygotes is strong enough, a maximization of the frequency of acrocentrics may occur (Hatfield et al., 1992). However, hybrid zones are also known in which acrocentrics are entirely lacking (Fedyk et al., 1993; Narain and Fredga, 1996). Accordingly, it may be concluded that the mechanisms favouring acrocentrics and metacentrics in hybrid populations are not at equilibrium. There are-apparently-certain hybrid zones in which selection acts more powerfully against complex heterozygotes, thereby limiting the influence of meiotic drive, as well as others in which the more moderate selection pressure against the heterozygotes allows meiotic drive to prevail over any trend towards acrocentrics being favoured. In contrast, at the edge of contact zones, preferential segregation may be effective in eliminating of acrocentric chromosomes from the populations, as could be observed around the OxfordHermitage hybrid zone (Searle, 1986a).

Preferential segregation of $X$ chromosomes has been reported in complex heterozygotes forming pentavalent chain configurations (CV) during meiosis (Fedyk et al., 2005). In contrast, both homozygous and heterozygous shrews with meiotic quadrivalents (CIV and RIV + CIV) display segregation of sex chromosomes that do not differ significantly from 1:1 (Fedyk et al., 2005). Searle (1986b) also reported equal segregation of sex chromosomes among simple $\mathrm{Rb}$ heterozygotes. These data suggested to Fedyk et al. (2005) that the chromosomes forming longer (at least CV) meiotic chains interact with chromosome Y1, which most often occurs as the univalent (Searle 1986b; Banaszek et al., 2002; Fedyk et al., 2005), giving greater mortality of MII cells with Y1Y2 chromosomes. Therefore, the preferential segregation of $X$ chromosomes in eight out of 12 of the studied simple $\mathrm{Rb}$ heterozygote male subjects (Table 3 ) is a surprise. When this new finding is taken into account, we are led to the paradoxical conclusion that, among the male subjects that form complexes of even numbers of autosomes conjugating in common (meiotic bivalents and quadrivalents), the normal (1:1) segregation of sex chromosomes occurs, while disturbed segregation in favour of $\mathrm{X}$ chromosomes takes place in males whose meiotic complexes are formed by odd numbers of autosomes (trivalents and pentavalents). Nonetheless, this conclusion seems improbable, so it is perhaps better to presume that in the material for the previous study (Fedyk et al., 2005)—comprising two CIV hybrids and one RIV + CIV-sex chromosome segregation was, by pure chance, close to $1: 1$, as in the case of several CV hybrids (Fedyk et al., 2005) and simple heterozygous individuals (the present study). If not, we should suppose that, irrespective of their size, odd-numbered complexes of chromosomes exert a disruptive influence on the segregation of sex chromosomes. This issue will only be resolved on the basis of re-examination of a large sample of CIV and/or RIV hybrids.

\section{Acknowledgements}

We thank U Bajkowska MSc for her assistance in laboratory and in maintaining the shrews, and DB Roszczenko MSc for her help in microscopic analyses. Our special thanks are directed to Professor M Konarzewski and Professor JB Searle and two anonymous reviewers for their valuable comments and improving our English. This study was supported by the Polish State Committee for Scientific Research within the Project No. 3PO4C 05823.

\section{References}

Banaszek A (1994). The structure of the contact zone between the chromosomal races Drużno and Łegucki Młyn in the common shrew (Sorex araneus) in north-eastern Poland. Folia Zoologica 43 (Suppl 1): 11-19.

Banaszek A, Fedyk S, Fiedorczuk U, Szałaj KA, Chętnicki W (2002). Meiotic studies of male common shrews (Sorex 
araneus L.) from a hybrid zone between chromosome races. Cytogenet Genome Res 96: 40-44.

Bengtsson BO (1980). Rates of karyotype evolution in placental mammals. Hereditas 92: 37-47.

Evans EP, Breckon G, Ford CE (1964). An air-drying method for meiotic preparations from mammalian testes. Cytogenetics 3: 289-294.

Fedyk S (1980). Chromosome polymorphism in a population of Sorex araneus L. at Białowieża. Folia biologica (Kraków) 28 83-120.

Fedyk S (1986). Genetic differentiation of Polish populations of Sorex araneus L. II. Possibilities of gene flow between chromosome races. Bull Acad Pol Sci, Biol Sci 34: 161-171.

Fedyk S (1987). Hybrid origin of some local chromosome races of Sorex araneus. Abstracts of the 1st Meeting of International Sorex araneus Cytogenetics Committee (ISACC), Oxford.

Fedyk S (1995). Regional differentiation and hybrid zones between chromosomal races of Sorex araneus L. in northeastern Poland. Dissertationes Universitatis Varsoviensis 439: 1-125. Białystok (in Polish).

Fedyk S, Bajkowska U, Chẹtnicki W (2005). Sex chromosome meiotic drive in hybrid males of the common shrew (Sorex araneus). Folia biologica (Kraków) 53: 133-141.

Fedyk S, Zajkowska M, Chętnicki W (1993). Study of a contact between two chromosomally monomorphic races of Sorex araneus L. (common shrew). Heredity 71: 221-226.

Felsenstein J, Yokoyama S (1976). The evolutionary advantage of recombination. II. Individual selection for recombination. Genetics 83: 845-859.

Fredga K, Narain Y (2000). The complex hybrid zone between the Abisko and Sidensjö chromosome races of Sorex araneus in Sweden. Biol J Linn Soc 70: 285-307.

Gropp A, Winking H (1981). Robertsonian translocations: cytology, meiosis, segregation patterns and biological consequences of heterozygosity. Symp Zool Soc Lond 47: 141-181.

Hatfield T, Barton N, Searle JB (1992). A model of a hybrid zone between two chromosomal races of the common shrew (Sorex araneus). Evolution 46: 1129-1145.

Hedrick PW (1981). The establishment of chromosomal variants. Evolution 35: 322-332.

King M (1993). Species Evolution. The Role of Chromosome Change. Cambridge University Press, Cambridge.

Lukáčová L, Piálek J, Zima J (1994). A hybrid zone between the Ulm and Drnholec karyotypic races of Sorex araneus in the Czech Republic. Folia Zoologica 43 (Suppl 1): 37-42.
Mercer SJ, Searle JB (1994). Captive breeding of the common shrew (Sorex araneus) for chromosomal analysis. In: Merrit JF, Kirkland Jr GL, Rose RK (eds). Advances in the Biology of Shrew. Carnegie Mus Nat History: Pittsburgh. pp 271-276.

Moska M (2003). A hybrid zone between the chromosomal races Łegucki Młyn and Popielno of the common shrew in northeastern Poland: preliminary results. Acta theriol 48: 441-455.

Narain Y, Fredga K (1996). A hybrid zone between the Hällefors and Uppsala chromosome races of Sorex araneus in central Sweden. Hereditas 125: 137-145.

Seabright M (1971). A rapid banding technique for human chromosomes. Lancet 2: 971-972.

Searle JB (1986a). Preferential transmission in wild common shrews (Sorex araneus), heterozygous for Robertsonian rearrangements. Genet Res Cambr 47: 147-148.

Searle JB (1986b). Meiotic studies of Robertsonian heterozygotes from natural populations of the common shrew, Sorex araneus L. Cytogenet Cell Genet 41: 154-162.

Searle JB (1986c). Factors responsible for a karyotypic polymorphism in the common shrew, Sorex araneus. Proc Roy Soc Lond B 229: 277-298.

Searle JB, Fedyk S, Fredga K, Hausser J, Volobouev VT (1991). Nomenclature for the chromosomes of the common shrew (Sorex araneus). Mem Soc vaud Sc Nat 19: 13-22.

Searle JB (1993). Chromosomal hybrid zones in eutherian mammals. In: Harrison RG (ed). Hybrid Zones and the Evolutionary Process. Oxford Univ Press: Oxford. pp 309-353.

Szałaj KA, Fedyk S, Banaszek A, Chętnicki W, Ratkiewicz M (1996). A hybrid zone between two chromosome races of the common shrew, Sorex araneus, in eastern Poland: preliminary results. Hereditas 125: 169-176.

Tegelström H, Searle J, Brookfield J, Mercer S (1991). Multiple paternity in wild common shrews (Sorex araneus) is confirmed by DNA - fingerprinting. Heredity 66: 373-379.

Wallace BMN (2003). The effect of heterozygosity, genic or chromosomal, on fertility in the common shrew (Sorex araneus) and house mouse (Mus musculus domesticus). Mammalia 68: 301-306.

Wyttenbach A, Borodin P, Hausser J (1998). Meiotic drive favors Robertsonian metacentric chromosomes in the common shrew (Sorex araneus, Insectivora, Mammalia). Cytogenet Cell Genet 83: 199-206.

Wyttenbach A, Hausser J (1996). The fixation of metacentric chromosomes during the chromosomal evolution of the common shrew (Sorex araneus, Insectivora). Hereditas 125: 209-217. 